\title{
The cellular uptake mechanism, intracellular transportation, and exocytosis of polyamidoamine dendrimers in multidrug-resistant breast
} cancer cells

\author{
This article was published in the following Dove Press journal: \\ International Journal of Nanomedicine \\ 3 August 2016 \\ Number of times this article has been viewed
}

Jie Zhang'
Dan Liu'
Mengjun Zhang'
Yuqi Sun',2
Xiaojun Zhang'
Guannan Guan'
Xiuli Zhao'
Mingxi Qiao'
Dawei Chen'
Haiyang Hu'
'Department of Pharmaceutics, School
of Pharmacy, Shenyang Pharmaceutical
University, Shenyang, 'Department of
Pharmaceutics, School of Pharmacy,
Liaoning Medical University, Jinzhou,
Liaoning Province, People's Republic
of China

of China
Correspondence: Haiyang Hu;

Dawei Chen

Department of Pharmaceutics, School of Pharmacy, Shenyang Pharmaceutical University, 103 Wenhua Road, Shenyang I I0016, People's Republic of China Tel +86242398 6308; +862423986306 Fax +86242398 6308; +862423986306 Email haiyang_hu@hotmail.com; chendawei@syphu.edu.cn

\begin{abstract}
Polyamidoamine dendrimers, which can deliver drugs and genetic materials to resistant cells, are attracting increased research attention, but their transportation behavior in resistant cells remains unclear. In this paper, we performed a systematic analysis of the cellular uptake, intracellular transportation, and efflux of PAMAM- $\mathrm{NH}_{2}$ dendrimers in multidrug-resistant breast cancer cells (MCF-7/ADR cells) using sensitive breast cancer cells (MCF-7 cells) as the control. We found that the uptake rate of PAMAM-NH $\mathrm{N}_{2}$ was much lower and exocytosis of PAMAM-NH ${ }_{2}$ was much greater in MCF-7/ADR cells than in MCF-7 cells due to the elimination of PAMAM-NH $\mathrm{NH}_{2}$ from P-glycoprotein and the multidrug resistance-associated protein in MCF-7/ADR cells. Macropinocytosis played a more important role in its uptake in MCF-7/ADR cells than in MCF-7 cells. PAMAM-NH aggregated and became more degraded in the lysosomal vesicles of the MCF-7/ADR cells than in those of the MCF-7 cells. The endoplasmic reticulum and Golgi complex were found to participate in the exocytosis rather than endocytosis process of PAMAM- $\mathrm{NH}_{2}$ in both types of cells. Our findings clearly showed the intracellular transportation process of PAMAM-NH $\mathrm{N}_{2}$ in MCF-7/ADR cells and provided a guide of using PAMAM-NH${ }_{2}$ as a drug and gene vector in resistant cells.
\end{abstract}

Keywords: PAMAM dendrimers, multidrug resistance, endocytosis, intracellular transportation, exocytosis

\section{Introduction}

Cancer remains a serious health threat. For the treatment of cases of inoperable and advanced-stage cancer, chemotherapy has been the optimal treatment choice. ${ }^{1}$ However, the major obstacle to successful chemotherapy for cancer treatment is multidrug resistance (MDR) in tumor cells. Considerable research effort has been devoted to overcome the MDR. ${ }^{2}$ Compared with other efforts, the nanocarriers can overcome the MDR by multiple approaches and attract more attention. ${ }^{3,4}$ Nanocarriers, such as polymeric micelles, ${ }^{5}$ liposomes, ${ }^{6}$ nanoparticles, ${ }^{7}$ and dendrimers,${ }^{8}$ are widely used to combat MDR in cancer.

Terminal amino groups of polyamidoamine (PAMAM) dendrimers have emerged as one of the most promising and innovative polymeric nanocarriers for reversing MDR owing to their distinct branched architecture and positive surface charge. ${ }^{9}$ PAMAM-NH${ }_{2}$ dendrimers are able to encapsulate chemotherapeutic drugs in their interior. For example, Yabbarov et al synthesized a three-component delivery system comprising a vector protein (recombinant receptor-binding fragment of 
alpha-fetoprotein), PAMAM dendrimer, and antitumor antibiotic doxorubicin (DOX), and showed it to exhibit a degree of high cytotoxic activity against human ovarian adenocarcinoma cell lines: DOX-sensitive SKOV3 cells and DOX-resistant SKVLB cells. ${ }^{8}$ The use of PAMAM-NH dendrimers as a gene vector to overcome MDR has also attracted research attention. They can bind the negative DNA/ RNA that downregulates the expression of MDR genes to restore drug sensitivity ${ }^{2}$ and, at the same time, encapsulate the chemotherapeutic drug ${ }^{9}$ to kill the drug-resistant tumor cells. Han et al synthesized PAMAM-hyaluronic acid to deliver DOX effectively and a major vault protein that targets smallinterfering RNA, and demonstrated that this drug delivery system can downregulate major vault protein expression and improve DOX chemotherapy in multidrug-resistant breast cancer cells (MCF-7/ADR cells). ${ }^{10}$ Zheng et al synthesized amine-terminated generation-5 PAMAM dendrimer-modified selenium nanoparticles and dual-delivered mdr1 siRNA and cisplatin (cis-diamminedichloroplatinum-[II]), which was demonstrated to significantly downregulate P-glycoprotein (P-gp) and MDR-associated protein expression and enhance cytotoxicity in a drug-resistant cancer cell line (A549/ cis-diamminedichloroplatinum-[II] cells). ${ }^{11}$

Our laboratory has also conducted a number of studies on reversing MDR in cancer ${ }^{12}$ and has prepared PAMAM/ HMGB1/pDNA nanocomplexes that can be used as high-efficiency gene carriers in vitro/vivo with high transfection and expression efficiency in sensitive breast cancer cells (MCF-7 cells). ${ }^{13}$ We have further applied PAMAM/HMGB1/ pDNA nanocomplexes to multidrug-resistant breast cancer cells (MCF-7/ADR cells). Interestingly, we found the transfection and expression efficiency of PAMAM/HMGB1/pDNA nanocomplexes in MCF-7/ADR cells to be significantly lower than that in MCF-7 cells, which indicates that the transportation process of PAMAM- $\mathrm{NH}_{2}$ dendrimers in drug-resistant tumor cells is different from that in tumor cells. Many studies have reported the transportation of PAMAM-NH $\mathrm{N}_{2}$ dendrimers in tumor cells. For example, Perumal et al showed that the cellular uptake pathway and distribution of PAMAM-NH dendrimers are different from those of other dendrimers in Caco-2 cells. ${ }^{14}$ Albertazzi et al have extensively investigated PAMAM- $\mathrm{NH}_{2}$ dendrimer internalization in HeLa cells and extended their observations by evaluating the interactions of these dendrimers with four different cell lines: human hepatocarcinoma liver carcinoma HepG2 cells, neuronal-like PC12 cells, and two primary cultures (MRC5 human lung fibroblast and astrocytes). ${ }^{15}$ However, little information is available on the cellular trafficking of PAMAM- $\mathrm{NH}_{2}$ dendrimers in resistant tumor cells.
The drug efficiency in tumor cells and the design of carriers are determined by the transportation of drug carrier in cells. Thus, it is necessary to explore whether the cellular transportation process of PAMAM- $\mathrm{NH}_{2}$ dendrimer in resistant tumor cells is different from the normal tumor cells. In this study, fluorescein isothiocyanate (FITC) was used to label PAMAM-G4.0- $\mathrm{NH}_{2}$ dendrimers. Using sensitive cells (MCF-7 cells) as a control, we performed systematic analysis of the cellular uptake, intracellular transportation, and efflux of PAMAM-NH $\mathrm{N}_{2}$ dendrimers in multidrug-resistant breast cells (MCF-7/ADR cells). Our aim was to support the rational design of PAMAM- $\mathrm{NH}_{2}$-based drug delivery systems to reverse MDR.

\section{Materials and methods \\ Materials}

PAMAM-G4-NH ${ }_{2}$, PAMAM-G4-OH, FITC, verapamil (VRP), fumitremorgin C (FTC), MK571, chlorpromazine, sodium azide, 2-deoxyglucose, ammonium chloride, brefeldin A, monensin, and bafilomycin A1 were purchased from Sigma-Aldrich Co. (St Louis, MO, USA). Dulbecco's Modified Eagle's Medium (DMEM) growth medium, Roswell Park Memorial Institute 1640 (RPMI-1640) growth medium, fetal bovine serum, and penicillin-streptomycin were purchased from Gibco BRL (Gaithersberg, MD, USA). Acridine Orange (AO) was purchased from DingGuo Biotechnology Co., Ltd. (Beijing, People's Republic of China). Hoechst 33258 and LysoTracker Red dye were purchased from Beyotime Biotechnology Co., Ltd. (Nantong, People's Republic of China). All other chemicals were commercially available reagents of at least analytical grade.

\section{FITC-labeled PAMAM-G4-NH dendrimer}

PAMAM-G4-NH ${ }_{2}$ dendrimers were labeled with FITC, as previously described. ${ }^{16}$ FITC solution (in acetone) was added to the dendrimer solution (in carbonate buffer solution, $\mathrm{pH}$ 9.4) and stirred overnight in the dark at room temperature. The solution was then dialyzed against distilled water using $3.5 \mathrm{kDa}$ dialysis membranes to remove the free FITC.

\section{FITC-labeled PAMAM-G4-OH dendrimers}

Appropriate quantities of PAMAM-G4-OH and FITC were dissolved in anhydrous dimethyl sulfoxide. 1-(3Dimethylaminopropyl)-3-ethylcarbodiimide and 4-dimethylaminopyridine were also dissolved in anhydrous dimethyl sulfoxide and added to the PAMAM-G4-OH solution. The reaction mixture was stirred for 3 days at room temperature 
and then dialyzed against distilled water using $3.5 \mathrm{kDa}$ dialysis membranes to remove the free FITC. ${ }^{14}$

\section{Cell culture}

The MCF-7 and MCF-7/ADR cells were maintained in DMEM growth medium and RPMI-1640 growth medium, respectively, which were supplemented with $20 \%$ fetal bovine serum and penicillin $(100 \mathrm{U} / \mathrm{mL})$-streptomycin $(100 \mu \mathrm{g} / \mathrm{mL})$. All cells were incubated at $37^{\circ} \mathrm{C}$ in a humidified atmosphere containing $5 \% \mathrm{CO}_{2}$.

For the flow cytometric experiments, the cells were seeded in six-well culture plates at a density of $1 \times 10^{6}$ cells/well for 24 hours to allow cell attachment. For the laser scanning confocal microscope (LSCM) examinations, they were seeded on $24 \mathrm{~mm}$ cover slips in six-well culture plates at a density of $4 \times 10^{5}$ cells/well and allowed to grow until a confluence of $60 \%-70 \%$ was obtained.

\section{MTT assay}

The MCF-7 and MCF-7/ADR cells were seeded separately in 96-well plates at a density of $6 \times 10^{3}$ cells per well in a humidified atmosphere with $5 \% \mathrm{CO}_{2}$ at $37^{\circ} \mathrm{C}$ and incubated overnight. Then, the medium was replaced with fresh medium containing different concentrations of PAMAM- $\mathrm{NH}_{2}$. After incubation for 72 hours, $20 \mu \mathrm{L}$ MTT was added, and the cells were further incubated for 4 hours. The medium was subsequently removed completely, and $150 \mu \mathrm{L}$ dimethyl sulfoxide was added to dissolve the purple formazan crystals. Absorbance was measured at $490 \mathrm{~nm}$ using a multifunctional microplate reader (Tecan, Grödig, Austria). Cells without complex treatment served as the control group and results were expressed as a percentage viability of control cells.

\section{Time-dependence of cellular uptake}

After the MCF-7 and MCF-7/ADR cells had grown to a confluence of $80 \%-90 \%$, the medium was replaced with a fresh serum-free medium with FITC-labeled PAMAM-G4-NH $(10 \mu \mathrm{g} / \mathrm{mL})$. At different intervals, the cells were washed three times with phosphate-buffered saline (PBS) to remove the dendrimers from the cell surface. The cells were then harvested, centrifuged at 1,000 rpm for 5 minutes, and resuspended in PBS. They were analyzed using a BD FACS Caliber flow cytometer (FACSCAN, Becton Dickinson, San Jose, CA, USA).

\section{Influence of ATP-binding cassette (ABC) transporter inhibitors on cellular uptake}

The MCF-7 and MCF-7/ADR cells were preincubated with a fresh serum-free medium containing VRP, FTC, and MK571 (Table 1), then FITC-labeled PAMAM-G4-NH $(10 \mu \mathrm{g} / \mathrm{mL})$ was added and incubated for another 3 hours in a humidified atmosphere with $5 \% \mathrm{CO}_{2}$ at $37^{\circ} \mathrm{C}$. Finally, the cells were washed with PBS, centrifuged at 1,000 rpm for 5 minutes, resuspended in PBS, and analyzed using a BD FACS Caliber flow cytometer.

\section{Energy-dependence of cellular uptake}

The MCF-7 cells and MCF-7/ADR cells were seeded separately in six-well culture plates $\left(1 \times 10^{6}\right.$ cells/well $)$ in a humidified atmosphere with $5 \% \mathrm{CO}_{2}$ at $37^{\circ} \mathrm{C}$. After 24 hours, the cells were preincubated at $4^{\circ} \mathrm{C}$ for 1 hour or with sodium azide and 2-deoxyglucose for 1 hour at $37^{\circ} \mathrm{C}$. Subsequently, PAMAM- $\mathrm{NH}_{2}$-FITC $(10 \mu \mathrm{g} / \mathrm{mL})$ was added and incubated at $4^{\circ} \mathrm{C}$ or $37^{\circ} \mathrm{C}$ for an additional 3 hours. Finally, the samples were disposed and analyzed using a BD FACS Caliber flow cytometer.

\section{Uptake pathway studies using endocytic inhibitors}

Using a previously reported method, ${ }^{14,17}$ the $\mathrm{MCF}-7$ and MCF-7/ADR cells were preincubated with endocytic inhibitors at a given concentration (Table 1) for 30 minutes

Table I Inhibitors used in this study and their functions as well as concentrations

\begin{tabular}{lll}
\hline Inhibitors & Function & Concentration \\
\hline Verapamil & P-glycoprotein inhibitor & $10 \mu \mathrm{mol} / \mathrm{L}$ \\
Fumitremorgin C & MDR-associated protein inhibitor & $5 \mu \mathrm{mol} / \mathrm{L}$ \\
MK57I & Breast cancer resistance protein inhibitor & $50 \mu \mathrm{mol} / \mathrm{L}$ \\
Sodium azide and 2-deoxyglucose & Active transport inhibitor & $0.1 \% \mathrm{w} / \mathrm{v}$ and $50 \mathrm{mmol} / \mathrm{L}$ \\
Sucrose & Nonselectively endocytosis inhibitor & $450 \mathrm{mmol} / \mathrm{L}$ \\
Chlorpromazine & Clathrin-mediated endocytosis inhibitor & $10 \mu \mathrm{g} / \mathrm{mL}$ \\
Methyl- $\beta$-cyclodextrin & Caveolae-mediated endocytosis inhibitor & $10 \mu \mathrm{mol} / \mathrm{L}$ \\
Amiloride & Macropinocytosis inhibitor & $50 \mu \mathrm{mol} / \mathrm{L}$ \\
Brefeldin A & Blocks transport from endoplasmic reticulum to Golgi complex & $25 \mu \mathrm{g} / \mathrm{mL}$ \\
Monensin & Blocks transport from Golgi complex to plasma membrane & $32.5 \mu \mathrm{gg} / \mathrm{mL}$ \\
Bafilomycin AI & Inhibitor of endosomal acidification & $100 \mathrm{nmol} / \mathrm{L}$ \\
\hline
\end{tabular}

Abbreviation: MDR, multidrug resistance. 
in a humidified atmosphere with $5 \% \mathrm{CO}_{2}$ at $37^{\circ} \mathrm{C}$. Then, PAMAM-NH $\mathrm{H}_{2}$-FITC $(10 \mu \mathrm{g} / \mathrm{mL})$ was added to cells for another 3 hours. Finally, the cells were processed and examined using a BD FACS Caliber flow cytometer.

\section{Influence of intracellular transport inhibitors on endocytosis}

The MCF-7 and MCF-7/ADR cells were preincubated with brefeldin $\mathrm{A}$, monensin, and bafilomycin $\mathrm{A} 1$ at a given concentration $^{18}$ (Table 1) for 30 minutes in a humidified atmosphere with $5 \% \mathrm{CO}_{2}$ at $37^{\circ} \mathrm{C}$, and incubated with PAMAM-NH_-FITC $(10 \mu \mathrm{g} / \mathrm{mL})$ for another 3 hours. The cells were then processed and examined using a BD FACS Caliber flow cytometer.

\section{Colocalization with lysosomes}

The MCF-7 and MCF-7/ADR cells were seeded separately on cover slips in six-well culture plates $\left(1 \times 10^{6}\right.$ cells/well $)$ in a humidified atmosphere with $5 \% \mathrm{CO}_{2}$ at $37^{\circ} \mathrm{C}$. Once the cells had achieved a confluence of $60 \%-70 \%$, a fresh serumfree medium containing PAMAM-NH - FITC $(10 \mu \mathrm{g} / \mathrm{mL})$ was added, followed by incubation for $0.5,1$, and 5 hours. At different times, the cells were treated with LysoTracker Red for 30 minutes, and then washed three times with cold PBS, fixed with 4\% formaldehyde, and stained with Hoechst 33258 at room temperature. The samples were captured by LSCM (Olympus FV1000-IX81, Olympus Corporation, Tokyo, Japan).

\section{Endolysosomal membrane integrity}

Lysosomal membrane integrity was assessed using AO. ${ }^{19}$ The MCF-7 and MCF-7/ADR cells were grown separately on cover slips in six-well culture plates $\left(1 \times 10^{6}\right.$ cells/well $)$ in a humidified atmosphere with $5 \% \mathrm{CO}_{2}$ for 24 hours at $37^{\circ} \mathrm{C}$. The cells were exposed to PAMAM-NH - FITC for 2 hours, then rinsed with $\mathrm{PBS}$, followed by staining with $\mathrm{AO}$ $(5 \mu \mathrm{g} / \mathrm{mL})$ in $\mathrm{PBS}$ for 10 minutes at $37^{\circ} \mathrm{C}$. The cell images were captured by LSCM.

\section{Time-dependence of cellular exocytosis}

The MCF-7 and MCF-7/ADR cells were seeded separately in six-well culture plates at a density of $1 \times 10^{6}$ cells/well in a humidified atmosphere with $5 \% \mathrm{CO}_{2}$ for 24 hours at $37^{\circ} \mathrm{C}$ and incubated with PAMAM-NH - -FITC $(10 \mu \mathrm{g} / \mathrm{mL})$ for 3 hours. The cells were rinsed with PBS and immediately incubated with a fresh dendrimer-free medium for different lengths of time. Finally, the cells were washed with PBS and resuspended in PBS, and the samples were analyzed with a BD FACS Caliber flow cytometer.

\section{Exocytosis of PAMAM-NH $\mathrm{N}_{2}$ by LSCM}

The MCF-7 and MCF-7/ADR cells were separately seeded on cover slips in six-well culture plates to reach $70 \%$ confluence. The cells were incubated with PAMAM-NH - -FITC $(10 \mu \mathrm{g} / \mathrm{mL})$ in fresh serum-free medium for 3 hours. Subsequently, cells were rinsed with PBS and immediately incubated with fresh medium for 4 hours. For visualization by confocal laser scanning microscopy, the nucleuses were labeled with Hoechst 33258. Finally, the cells were washed with PBS and observed using LSCM.

\section{Analysis of PAMAM- $\mathrm{NH}_{2}$ exocytosis pathways}

The MCF-7 and MCF-7/ADR cells were seeded separately in six-well culture plates in a humidified atmosphere with $5 \% \mathrm{CO}_{2}$ at $37^{\circ} \mathrm{C}$ for 24 hours. The cells were then incubated with PAMAM-NH$H_{2}$-FITC $(10 \mu \mathrm{g} / \mathrm{mL})$ in a fresh serum-free medium for 3 hours, rinsed three times with cold PBS, and incubated in a fresh medium containing various inhibitors ${ }^{18}$ (the intracellular transport inhibitors in Table 1) for another 5 hours. Finally, the cells were washed with PBS and resuspended in PBS, and the samples were analyzed with a BD FACS Caliber flow cytometer.

\section{Statistical analysis}

All values are reported as the mean \pm standard deviation. The data were analyzed statistically via one-way analysis of variance and a Student's $t$-test using SPSS 13.0 software (SPSS Inc., Chicago, IL, USA). $P$-values $<0.05$ and $<0.01$ indicate statistically significant differences.

\section{Results and discussion Cytotoxicity of PAMAM- $\mathrm{NH}_{2}$} As shown in Figure 1, the viability of cells decreased with the increase of the PAMAM- $\mathrm{NH}_{2}$ concentration. At low concentrations $(10-50 \mu \mathrm{g} / \mathrm{mL})$, the viabilities of MCF-7 and MCF-7/ADR cells at 72 hours were $>85 \%$, indicating that $\mathrm{PAMAM}-\mathrm{NH}_{2}$ showed low cytotoxicity against MCF-7 and MCF-7/ADR cells at low concentration. At high concentrations $(100-1,000 \mu \mathrm{g} / \mathrm{mL})$, the viabilities of the two cells incubated with PAMAM- $\mathrm{NH}_{2}$ sharply decreased, demonstrating that the PAMAM-NH $\mathrm{N}_{2}$ exhibits significant concentration-dependent toxicity against MCF-7 and MCF-7/ADR cells. As reported previously, the positively 


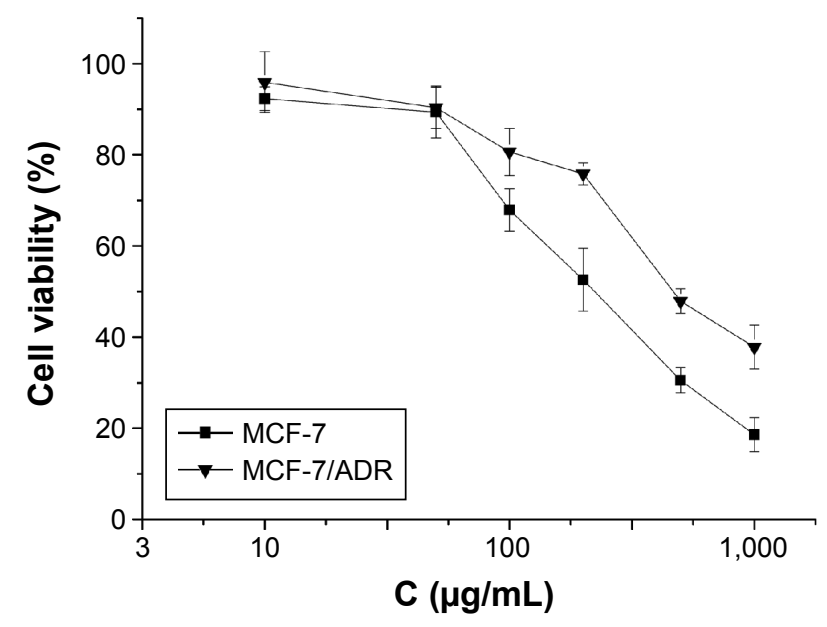

Figure I In vitro cytotoxicity of PAMAM- $\mathrm{NH}_{2}$ at different concentrations against MCF-7 and MCF-7/ADR cells for 72 hours (mean \pm SD, $n=6$ ) Abbreviation: SD, standard deviation.

charged amine groups on the surface of PAMAM-NH can interact with the negatively charged cell membranes, damaging the cell membranes and causing cell lysis. ${ }^{20}$ Figure 1 also shows that the viability of MCF-7/ADR cells is higher than that of MCF-7 cells at the high concentration of PAMAM-NH ${ }_{2}(200-1,000 \mu \mathrm{g} / \mathrm{mL})$. Figure 2 shows that the uptake rate of PAMAM-NH $\mathrm{N}_{2}$ in MCF-7/ADR cells was lower than that in MCF-7 cells. Thus, the high concentration of PAMAM- $\mathrm{NH}_{2}$ showed the lower cytotoxicity in MCF-7/ ADR cells. Moreover, $\mathrm{IC}_{50}$ of PAMAM-NH $\mathrm{N}_{2}$ in MCF-7 and MCF-7/ADR cells was $193 \pm 7.29$ and $462 \pm 5.37 \mu \mathrm{g} / \mathrm{mL}$, respectively. An amount of $10 \mu \mathrm{g} / \mathrm{mL}$ of PAMAM- $\mathrm{NH}_{2}$ was not toxic to MCF-7 and MCF-7/ADR cells and could be used in other studies in this report.

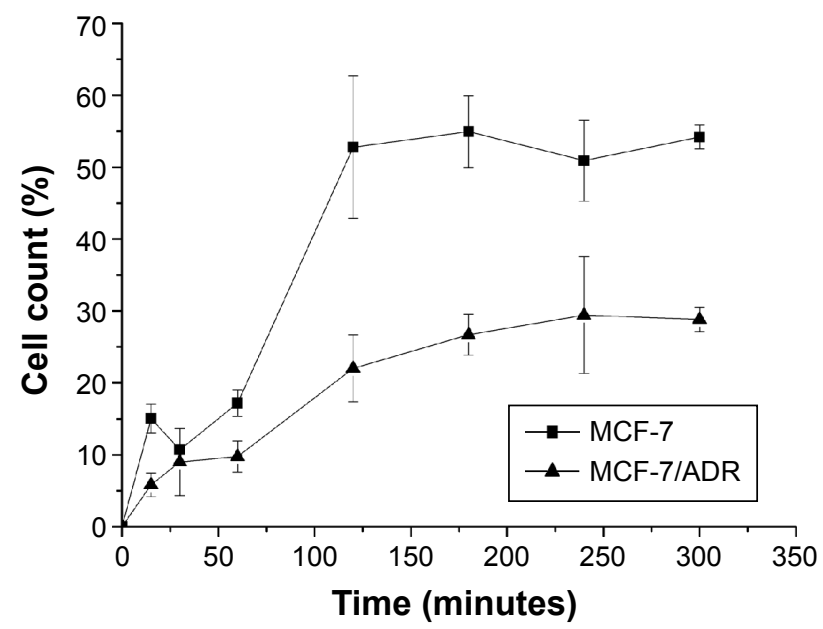

Figure 2 The effects of incubation time on PAMAM- $\mathrm{NH}_{2}$ internalization (mean $\pm \mathrm{SD}, \mathrm{n}=3$ ).

Abbreviation: SD, standard deviation.

\section{Time-dependence of cellular uptake of PAMAM- $\mathrm{NH}_{2}$}

To investigate the different cellular uptake efficiency of PAMAM-NH $\mathrm{N}_{2}$ by MCF-7 cells and MCF-7/ADR cells, we ensured that $\sim 13.67 \%$ of the amine groups on surface of the PAMAM dendrimers were modified with FITC. It is reported that the FITC is a pH-dependent dye. ${ }^{21}$ The protonation of the carboxylate radical can decrease the fluorescent intensity. The endosomal/lysosomal $\mathrm{pH}_{\left(\mathrm{pH}_{\mathrm{v}}\right)}$ is lower than the cytosolic $\mathrm{pH}$ $\left(\mathrm{pH}_{\mathrm{i}}\right)$ in one type of cell. In our study, we detected the fluorescent intensity of FITC-labeled PAMAM-NH $\mathrm{N}_{2}$ in MCF-7 and MCF-7/ADR cells, which included the fluorescence from the cytoplasm and endosomes/lysosomes in each cell, and we did not compare the fluorescent intensity of FITC-labeled PAMAM- $\mathrm{NH}_{2}$ between the endosomes/lysosomes and the cytoplasm. Martínez-Zaguilán et al detected the $\mathrm{pH}_{\mathrm{v}}$ and $\mathrm{pH}$ in the drug-sensitive (MCF-7/S) and -resistant (MCF-7/DOX and MCF-7/MITOX) cells, and point out that the differences in steady-state $\mathrm{pH}_{\mathrm{i}}$ and $\mathrm{pH}_{\mathrm{v}}$ between the three cell lines are not significant. ${ }^{22}$ Thus, in our study, the $\mathrm{pH}$-dependence of FITC had no effect on the fluorescent intensity detected in MCF-7 and MCF-7/ADR cells.

As shown in Figure 2, the cellular uptake efficiency of PAMAM-NH ${ }_{2}$ finally reaches plateaus both in MCF-7 and MCF-7/ADR cells. The increasing rate of PAMAM- $\mathrm{NH}_{2}$ over 120 minutes was slower, and the final uptake efficiency much lower in the MCF-7/ADR cells than in the MCF-7 cells. It is reported that the nonspecific binding would be expected due to ionic interaction. The cation on the surface of PAMAM-NH can bind with proteoglycans on the cell membranes. Seib et al report that low temperature can block the internalization and not influence the external binding at surface. Thus, the cellular uptake at $4^{\circ} \mathrm{C}$ can represent the amounts of the external binding. ${ }^{21}$ We have detected the cellular uptake of PAMAM-NH ${ }_{2}$ by the MCF-7 cells and MCF-7/ADR cells at $4{ }^{\circ} \mathrm{C}$ (Figure 3). The uptake rates of PAMAM- $\mathrm{NH}_{2}$ have reached the equilibrium after incubation with PAMAM-NH for 3 hours in MCF-7 cells and MCF-7/ADR cells, which indicated that the binding at the cell surface has also reached the saturation. Thus, the surface binding contributed 38.0\% and $20.9 \%$ to total tested fluorescence for MCF-7 cells and MCF-7/ADR cells, respectively. The amounts of PAMAM$\mathrm{NH}_{2}$ binding at the MCF-7/ADR cell surface were lower than that at the MCF-7 cells surface. The binding at the cell surface could not be ruled out in all assays. Thus, a portion of the lower tested PAMAM-NH ${ }_{2}$ uptake efficiency at MCF-7/ADR cells was due to the lower binding at the MCF-7/ADR cells. 


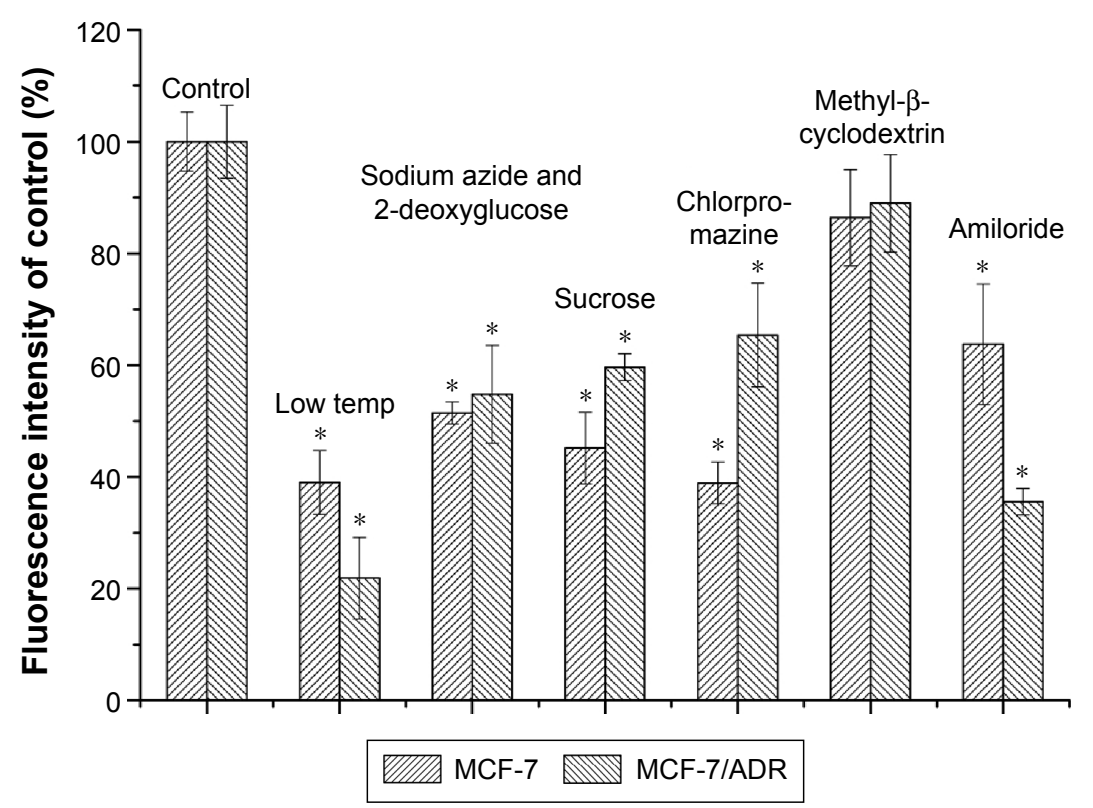

Figure 3 The effects of different endocytosis inhibitors on the endocytosis of PAMAM-NH $\mathrm{N}_{2}$.

Notes: The control samples were cells with no inhibitor pretreatment and percent of intracellular fluorescence intensity calculated considering the intensity of control samples as $100 \%$. *Indicates $P<0.05$ vs control group (mean $\pm S D, n=3$ ).

Abbreviations: SD, standard deviation; temp, temperature.

Additionally, the excretion always exists throughout the time-dependence endocytosis process, and the uptake plateaus off once the uptake and excretion reach equilibrium. ${ }^{23} \mathrm{We}$ speculated the excretion from the MCF-7/ADR cells might be higher than that from MCF-7 cells.

\section{Influence of $A B C$ transporter inhibitors on cellular uptake}

The overexpression of $\mathrm{ABC}$ proteins, which can increase drug efflux, such as P-gp, MDR-associated protein, and breast cancer resistance protein, is one of the MDR mechanisms in multidrug-resistant cells. ${ }^{24}$ To investigate the effect of these $\mathrm{ABC}$ proteins on the uptake of PAMAM- $\mathrm{NH}_{2}$, we preincubated the MCF-7 and MCF-7/ADR cells with ABC protein inhibitors ${ }^{25,26}$ (Table 1). As shown in Figure 4, compared with the controls which were MCF-7/ADR cells with no inhibitor pretreatment, the cellular uptake efficiency of PAMAM-NH in MCF-7/ADR cells increased to an extremely significant degree with the addition of $\operatorname{VRP}(P<0.01)$ and to a significant degree with the addition of FTC $(P<0.05)$, but the addition of MK571 effected no change in such efficiency. The cellular uptake rates of PAMAM-NH ${ }_{2}$ in MCF-7 cells had no significant changes $(P>0.05)$ with the addition of VRP, FTC, and MK571 compared with the control. The MCF-7 cells had a significant decrease of $\mathrm{ABC}$ protein expression compared to the MCF-7/ADR cells. ${ }^{27}$ The VRP, FTC, and MK571 that separately inhibit the P-pg, MDR-associated protein, and breast cancer resistance protein have no effect on the uptake rates of PAMAM-NH $\mathrm{N}_{2}$ in MCF-7 cells. The higher uptake efficiency of PAMAM-NH $\mathrm{N}_{2}$ in MCF-7/ADR cells with the addition of VRP and FTC demonstrated that PAMAM-NH can be repulsed by P-gp and MDR-associated protein, and confirmed that MDR influenced the uptake of PAMAM$\mathrm{NH}_{2}$ in MCF-7/ADR cells. The different cellular uptake rates of PAMAM-NH2 between MCF-7 and MCF-7/ADR cells (Figure 2) should partly come from the elimination of PAMAM-NH2 by P-pg and the MDR-associated protein in MCF-7/ADR cells $(P<0.01)$.

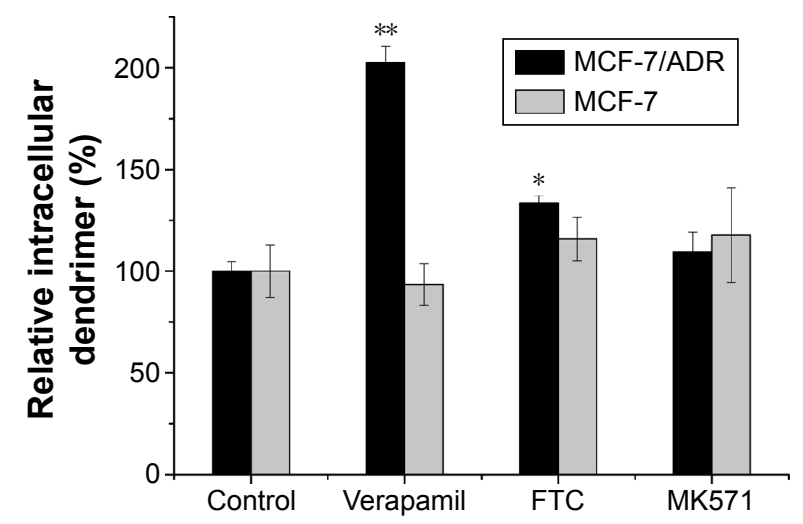

Figure 4 The effects of different $A B C$ transporter inhibitors on the endocytosis of PAMAM- $\mathrm{NH}_{2}$.

Notes: The control samples were cells with no inhibitors pretreatment and percent of intracellular fluorescence intensity calculated considering the intensity of control samples as $100 \%$. *Indicates $P<0.05$ vs control group, **indicates $P<0.01$ vs control group (mean $\pm S D, n=3$ ).

Abbreviations: ABC, ATP-binding cassette; FTC, fumitremorgin C; SD, standard deviation. 
Earlier reports suggest that nanocarriers can bypass drug efflux by $\mathrm{ABC}$ transporters, as they are internalized via either nonspecific or specific endocytosis to overcome MDR. ${ }^{2}$ However, the results of the current study show that P-gp can eliminate PAMAM- $\mathrm{NH}_{2}$, which is contrary to previous reports. Previous reports indicated that dendrimers can change the cell membrane permeability and penetrate membranes. ${ }^{28}$ Moreover, three primary hypotheses for the uptake of polycationic nanoparticles into cells have been postulated in the literature: energy-dependent endocytosis, energy-dependent formation of nanoscale membrane holes, and energy-independent membrane translocation. ${ }^{29}$ Low temperatures $\left(\sim 4^{\circ} \mathrm{C}-6^{\circ} \mathrm{C}\right)$ have generally been considered to be evidence for the inhibition of an ATP-driven endocytosis process and cooling the lipid membranes results in a change from fluid phase to gel phase, and also inhibits hole formation in supported lipid bilayers. ${ }^{30}$ Meanwhile, sucrose can nonselectively inhibit endocytosis. ${ }^{16}$ Figure 3 showed that the uptake of PAMAM- $\mathrm{NH}_{2}$ decreased more at low temperature (to 20.9\%) compared with the pretreatment of sucrose (to 59.6\%) in MCF-7/ADR cells. The difference of the uptake rate between low temperature and the pretreatment of sucrose should be contributed to uptake pathway of the energy-dependent formation of nanoscale membrane holes. Therefore, besides the endocytosis, PAMAM-NH should be taken up into the cells through energy-dependent formation of nanoscale membrane holes and this portion of PAMAM-NH ${ }_{2}$ may not bypass P-gp.

\section{Energy-dependence of cellular uptake}

It is well known that a low temperature can reduce cell metabolism and that sodium azide and 2-deoxyglucose can block the production of ATP by interfering with the glycolytic and oxidative metabolic pathways of the cells. ${ }^{14}$ As shown in Figure 3, at a low incubation temperature, the cellular uptake of PAMAM-NH ${ }_{2}$ by the MCF-7 cells and MCF-7/ADR cells was significantly reduced relative to the control at $37^{\circ} \mathrm{C}$ $(P<0.05)$. Uptake by both types of cells was reduced to $\sim 50 \%$ with the addition of sodium azide and 2-deoxyglucose. These results indicate that the cellular uptake of PAMAM- $\mathrm{NH}_{2}$ is an energy-dependent process.

\section{Uptake pathway studies using endocytic inhibitors}

As reported previously, the uptake pathways can be divided into two groups: ${ }^{31}$ endocytic pathways and non-endocytic pathways. Several endocytic pathways that regulate cellular trafficking have been identified, including phagocytosis, clathrin-mediated endocytosis (CME), caveolae-mediated endocytosis (CvME), macropinocytosis, and clathrin- and caveolae-independent endocytosis. Phagocytosis exists primarily in professional phagocytes, such as macrophages, monocytes, neutrophils, and dendritic cells. In comparison, other non-phagocytic pathways, such as CME, CvME, and macropinocytosis, occur in almost every type of cell.

Exposing cells to hypertonic media with sucrose is known to nonselectively inhibit fluid-phase endocytosis. ${ }^{16}$ After the cells were treated with sucrose, significantly reduced uptake of PAMAM-NH $\mathrm{N}_{2}$ was observed in both types of cells (Figure 3). These results indicate that fluid-phase endocytosis is involved in the uptake of PAMAM- $\mathrm{NH}_{2}$ by MCF-7 cells and MCF-7/ADR cells.

Chlorpromazine interacts with clathrin from the coated pits and causes it to accumulate in late endosomes, consequently inhibiting coated pit endocytosis. ${ }^{32}$ As shown in Figure 3, the uptake of PAMAM-NH ${ }_{2}$ by both the MCF-7 and MCF-7/ADR cells was significantly blocked $(P<0.05)$ with the addition of chlorpromazine, which suggests that CME plays a role in the internalization of PAMAM-NH $\mathrm{NH}_{2}$ these cells. In comparison, the greater decrease in the uptake of PAMAM- $\mathrm{NH}_{2}$ in the MCF-7 cells indicates that the CME is more important for the internalization of PAMAM-NH in MCF-7 cells.

CvME begins in a special flask-shaped structure on the cell membrane called a caveola, which is a kind of cholesterol- and sphingolipid-rich smooth invagination. Methyl- $\beta$-cyclodextrin can deplete the cholesterol in the plasma membrane, resulting in the inhibition of $\mathrm{CvME} .{ }^{33} \mathrm{The}$ PAMAM-NH ${ }_{2}$ uptake rates in the MCF-7 and MCF-7/ADR cells treated with methyl- $\beta$-cyclodextrin did not exhibit a significant decrease (Figure 3), showing that CvME is not involved in the internalization of PAMAM- $\mathrm{NH}_{2}$ in these cells.

Amiloride can block the $\mathrm{Na}^{+} / \mathrm{H}^{+}$pump that is indispensable for macropinocytosis. ${ }^{34}$ As shown in Figure 3, the uptake of PAMAM- $\mathrm{NH}_{2}$ was significantly reduced when amiloride was added by $36 \%$ in the MCF- 7 cells $(P<0.05)$ and by $65 \%$ in the MCF-7/ADR cells $(P<0.05)$. Obviously, the macropinocytosis pathway is a primary PAMAM- $\mathrm{NH}_{2}$ uptake route in both types of cells. Additionally, the greater decrease in the uptake rate of PAMAM-NH $\mathrm{N}_{2}$ in the MCF-7/ADR cells shows that macropinocytosis plays a more important role in the internalization of PAMAM-NH $\mathrm{N}_{2}$ in MCF-7/ADR cells.

\section{Influence of intracellular transport inhibitors on endocytosis}

To investigate the contribution of the Golgi complex, endoplasmic reticulum (ER), and endosomal acidification to the 
endocytosis process of PAMAM-NH ${ }_{2}$, brefeldin A, monensin, and bafilomycin A1 were added as inhibitory agents. ${ }^{18}$

Brefeldin A, a fungal metabolite, blocks forward transportation between the ER and Golgi complex, ${ }^{35}$ whereas monensin, another inhibitor that is often used to disrupt the Golgi complex, has been shown to effectively block the transportation of macromolecules from the Golgi complex to the plasma membrane. ${ }^{36}$ As shown in Figure 5, the addition of brefeldin A and monensin did not influence the intracellular amount of PAMAM-NH${ }_{2}$, indicating that neither the ER nor Golgi complex participates in the endocytosis process of PAMAM-NH $\mathrm{N}_{2}$.

Bafilomycin A1, which is known to be an inhibitor of endosomal acidification, was added to investigate the effects of the acidification process on the endocytosis of PAMAM- $\mathrm{NH}_{2} \cdot{ }^{37}$ Figure 5 shows that the intracellular amount of PAMAM-NH ${ }_{2}$ increased in both the MCF-7 and MCF-7/ADR cells after bafilomycin A1 was added, suggesting that endosomal acidification can regulate the endocytosis process of PAMAM-NH${ }_{2}$. It has been reported that early endosomes mature into late endosomes and then into lysosomes following acidification. ${ }^{18}$ It is well known that lysosomes can degrade the cargo and that inhibiting endosomal acidification can prevent PAMAM-NH $\mathrm{N}_{2}$ from being transported to the lysosomes, thus leading to the avoidance of degradation. Hence, inhibiting endosomal acidification can increase the amount of PAMAM-NH$H_{2}$ remaining in the cells rather than increasing endocytosis. ${ }^{18}$

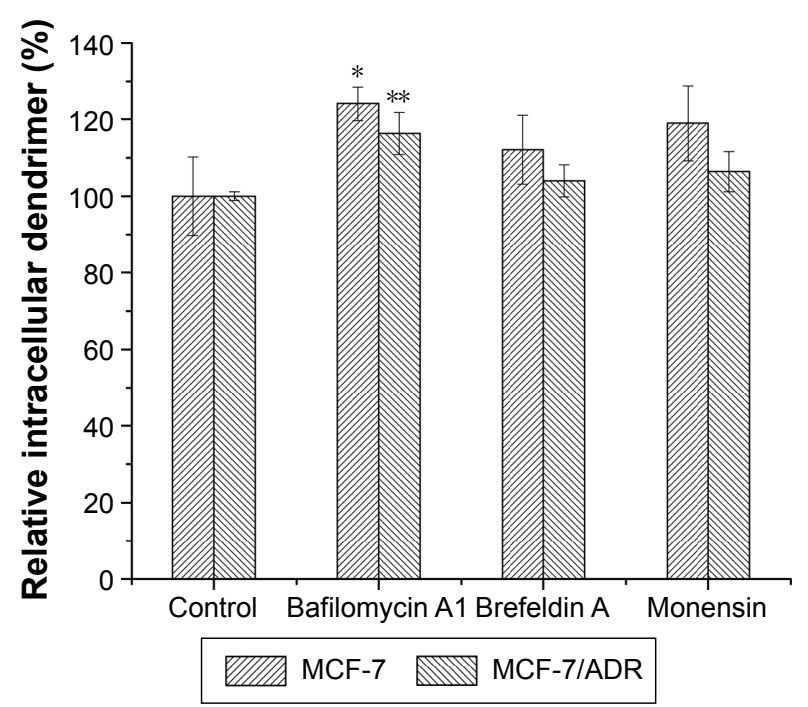

Figure $\mathbf{5}$ The effects of different intracellular transport inhibitors on the endocytosis of PAMAM- $\mathrm{NH}_{2}$.

Notes: The control samples were cells with no inhibitor pretreatment and percent of intracellular fluorescence intensity calculated considering the intensity of control samples as $100 \%$. *Indicates $P<0.05$ vs control group (mean $\pm S D, n=3$ ). **Indicates $P<0.0$ I vs control group.

Abbreviation: SD, standard deviation.
Inhibition of the ER and Golgi complex exerted negligible effects on the endocytosis of PAMAM-NH${ }_{2}$, which means that endocytosis is a facile procedure and independent of the intracellular process. ${ }^{18}$ In addition, compared with the controls, after the cells had been preincubated with bafilomycin A1, the increase in PAMAM-NH $\mathrm{N}_{2}$ was extremely significant $(P<0.01)$ in the MCF-7/ADR cells and significant $(P<0.05)$ in the MCF-7 cells, revealing that the lysosomes of MCF-7/ADR cells degrade more PAMAM-NH $\mathrm{H}_{2}$ than those of the MCF-7 cells and that endosomal acidification has a more important effect on the endocytosis of PAMAM-NH in MCF-7/ADR cells.

\section{Cellular colocalization with lysosomes}

The cells were labeled with a nucleus-selective dye (Hoechst 33258 , blue) and a dye selective for lysosomes (Lyso Tracker Red, red), respectively. Figure 6 shows the colocalization of PAMAM-NH$H_{2}$ with lysosomes after the cells had been incubated with FITC-labeled PAMAM- $\mathrm{NH}_{2}$ for varying time periods. From 0.5 to 5 hours, the green fluorescent intensity (PAMAM-NH ${ }_{2}$ ) gradually increased with time and was colocalized with red fluorescence, suggesting that PAMAM-NH is entrapped in lysosomes. Pixel intensity analysis of the colocalization showed that after 5 hours, $21.3 \%$ of all the green dendrimer fluorescence overlapped with the red LysoTracker fluorescence in the MCF-7/ADR cells and $11.43 \%$ of all the green dendrimer fluorescence overlapped with the red LysoTracker fluorescence in the MCF-7 cells (Figure 7), suggesting that the amount of PAMAM- $\mathrm{NH}_{2}$ transported into the lysosomes was greater in the MCF-7/ADR cells. Figure 6 also shows that a portion of more bright green fluorescence aggregation of PAMAM-NH $\mathrm{N}_{2}$ was found in MCF-7/ADR cells and the aggregation overlapped with lysosomes in the MCF-7/ADR cells, indicating that the PAMAM-NH aggregated in the lysosomal vesicles of the MCF-7/ADR cells. In contrast, the green fluorescence was evenly distributed in MCF-7 cells. Thus, compared with the MCF-7 cells, PAMAM-NH$H_{2}$ has greater difficulty to escape from the lysosomes in the MCF-7/ADR cells. The tested dendrimers in this study were taken up via CME in both types of cells. In the CME pathway, the PAMAM-NH $\mathrm{N}_{2}$ internalized from the plasma membrane is integrated into late endosomes and then delivered to lysosomes. ${ }^{38-40}$ Although PAMAM-NH has a proton sponge effect, the more complicated internal environment of lysosomes in resistant cells results in more difficult lysosomes escape in MCF-7/ADR cells.

The colocalization of green and blue fluorescence was also observed in both types of cells (Figure 6), showing 
A

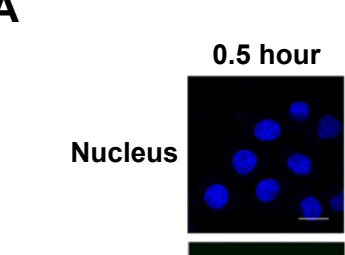

\section{MCF-7}

1 hour

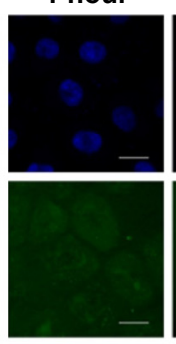

5 hours

PAMAM-NH
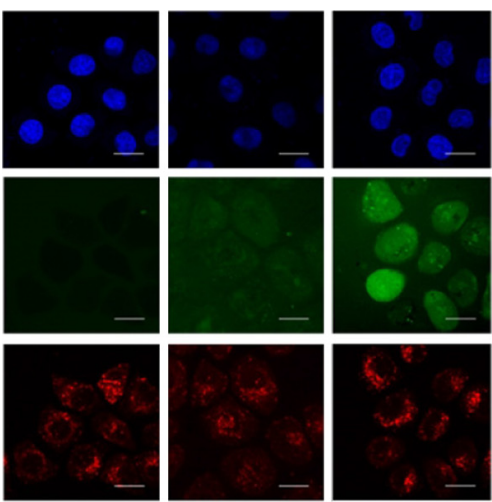

Lysosomes
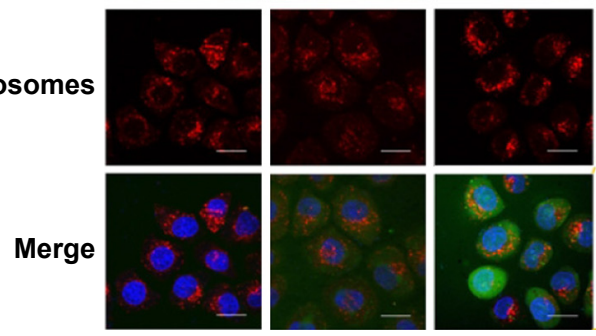

B
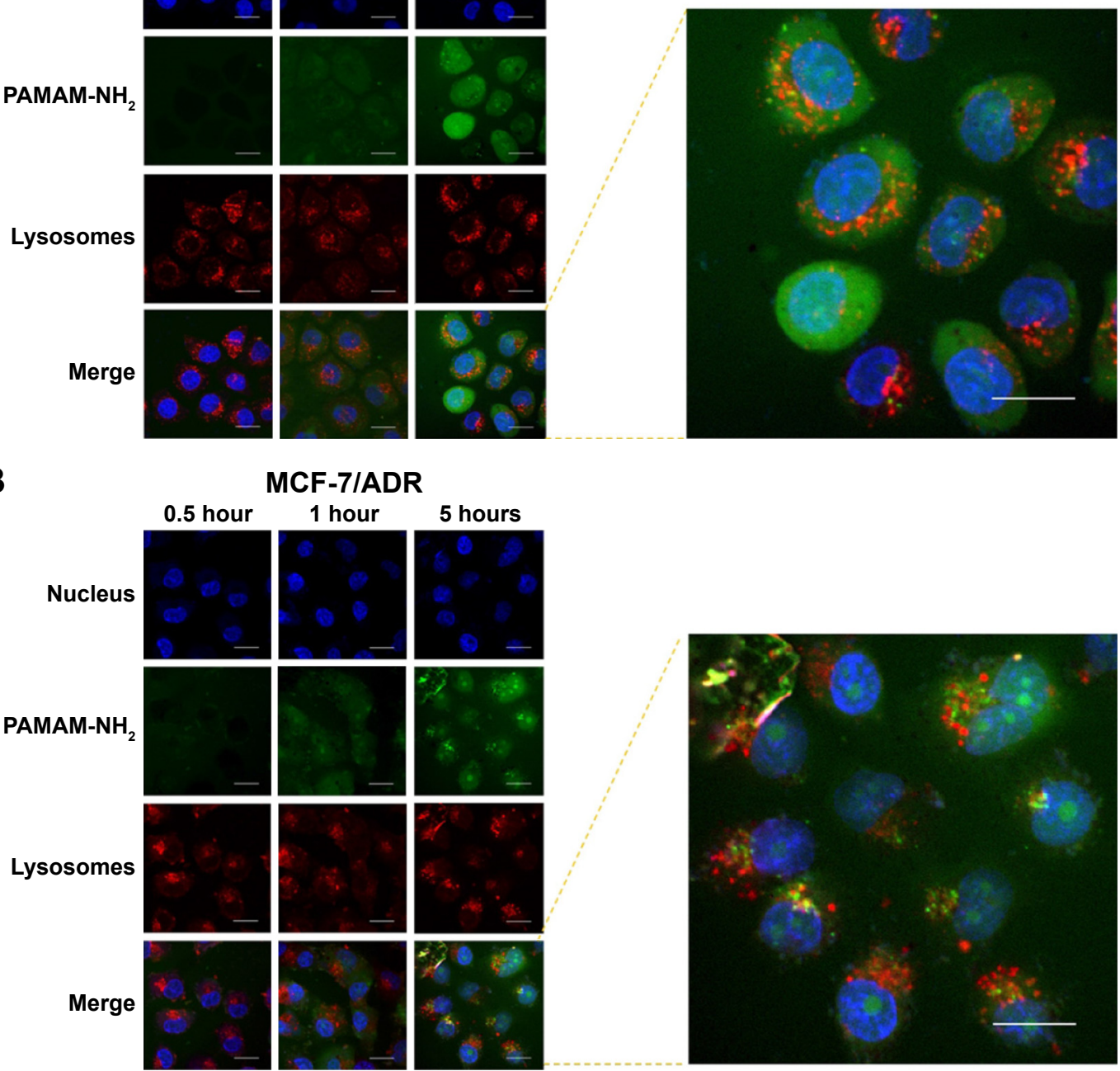

Figure 6 Colocalization of PAMAM-NH 2 with lysosomes in MCF-7 cells (A) and MCF-7/ADR cells (B) as a function of incubation time.

Notes: PAMAM- $\mathrm{NH}_{2}$ was green, the nucleuses were blue stained using Hoechst 33258, and the lysosomes were red stained using LysoTracker Red. The scale bar is $20 \mu \mathrm{m}$.

\section{MCF-7}

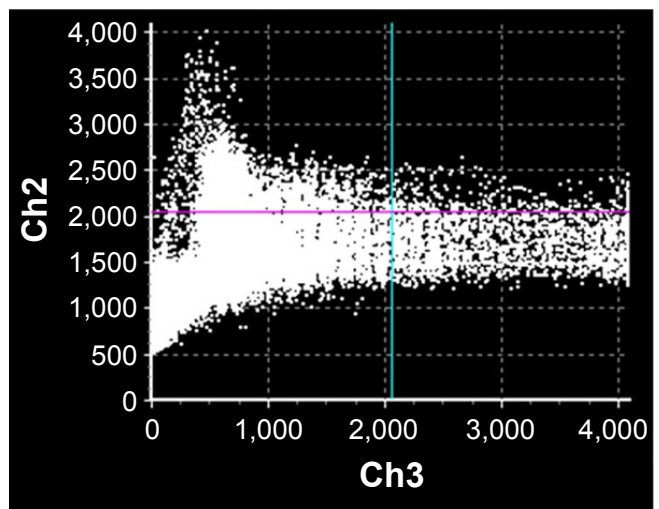

MCF-7IADR

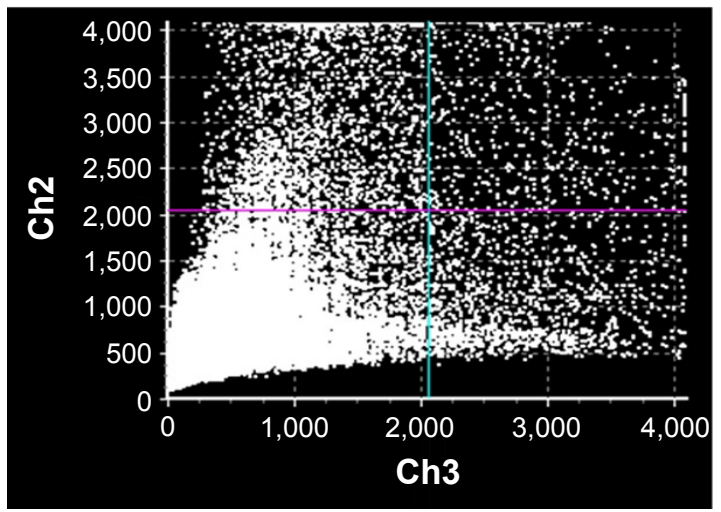

Figure 7 Scatter-plots of colocalization analysis in the MCF-7 and MCF-7/ADR cells at 5 hours.

Notes: $\mathrm{Ch} 2$ represents the PAMAM- $\mathrm{NH}_{2}$, and $\mathrm{Ch} 3$ represents the lysosomes.

Abbreviation: Ch, channel. 
that PAMAM-NH${ }_{2}$ can escape from lysosomes to enter the nucleus. Brunner et al reported that the polymers with a particle smaller than $28 \mathrm{~nm}$ can be transported into nuclei through nuclear core complex and the positively charged polymer can interact with the negatively charged lipid on the nuclear membrane, facilitating cationic polymer entry into the nuclear membrane. ${ }^{41}$ The diameter of tested PAMAM dendrimers was $\sim 5 \mathrm{~nm}$ and the PAMAM-NH${ }_{2}$ own positive charge on the surface, so the PAMAM- $\mathrm{NH}_{2}$ could more easily enter the nuclear membrane. PAMAM-NH ${ }_{2}$ also dispersed in cytosol. PAMAM-NH $\mathrm{N}_{2}$ was taken up by macropinocytosis in both types of cells. In the macropinocytosis pathway, macropinosomes without apparent coat structures fuse with the plasma membrane. ${ }^{42,43}$ The relationship between macropinosomes and lysosomes remains unclear because they are sometimes cell type-dependent. ${ }^{31}$ Therefore, the portion of PAMAM-NH $\mathrm{N}_{2}$ in cytosol is thought to be related to the macropinosomes.

\section{Endolysosomal membrane integrity}

To investigate the difference in endolysosomal membrane integrity between the MCF-7 and MCF-7/ADR cells after the addition of PAMAM-NH${ }_{2}$, the AO relocation technique was used. AO is a lysosomotropic base that produces a red fluorescent emission when it accumulates in acidic lysosomes. Disruption of the lysosomal membrane can be assessed by measuring the change in intracellular AO fluorescence. ${ }^{44}$ As previously reported, a high concentration $(100 \mu \mathrm{g} / \mathrm{mL})$ of
PAMAM-NH $\mathrm{N}_{2}$ solution was used as a positive control, as it has been shown to be capable of rupturing the endolysosomal membrane. ${ }^{45}$ As shown in Figure 8, in the control MCF-7 and MCF-7/ADR cells, the red-orange granules of the endolysosomes and diffuse green fluorescence of cytosol can be observed clearly. After adding $10 \mu \mathrm{g} / \mathrm{mL}$ of PAMAM-NH${ }_{2}$, both the MCF-7 and MCF-7/ADR cells released lysosomal content into the cytoplasm. However, the MCF-7 cells incubated with $10 \mu \mathrm{g} / \mathrm{mL}$ of PAMAM-NH $\mathrm{N}_{2}$ exhibited the same change as the positive control, but that of the MCF-7/ADR cells so incubated differed from the positive control. These results suggest that $10 \mu \mathrm{g} / \mathrm{mL}$ of PAMAM-NH$H_{2}$ can easily rupture the endolysosomal membrane in MCF-7 cells, but not that of MCF-7/ADR cells. Thus, PAMAM-NH 2 aggregates in the lysosomal vesicles of MCF-7/ADR cells and is degraded more in MCF-7/ADR cells.

\section{Exocytosis of PAMAM dendrimers}

Exocytosis has been reported to exist throughout the timedependent endocytosis process. ${ }^{23}$ Seib et al showed that there is no discernible exocytosis of PAMAM G 4.0 over 1 hour in B16f10 melanoma cells. ${ }^{21}$ In this study, we extended the time period and obtained different results. We detected the intracellular fluorescence intensity of PAMAM-NH $\mathrm{N}_{2}$ at different times (1, 3, 6, 9, 12, 18, and 24 hours) after its removal. As shown in Figure 9A, the exocytosis of PAMAM-NH in the MCF-7 cells reached a maximum at 3 hours. From 3 to 24 hours, no significant change was detected, and
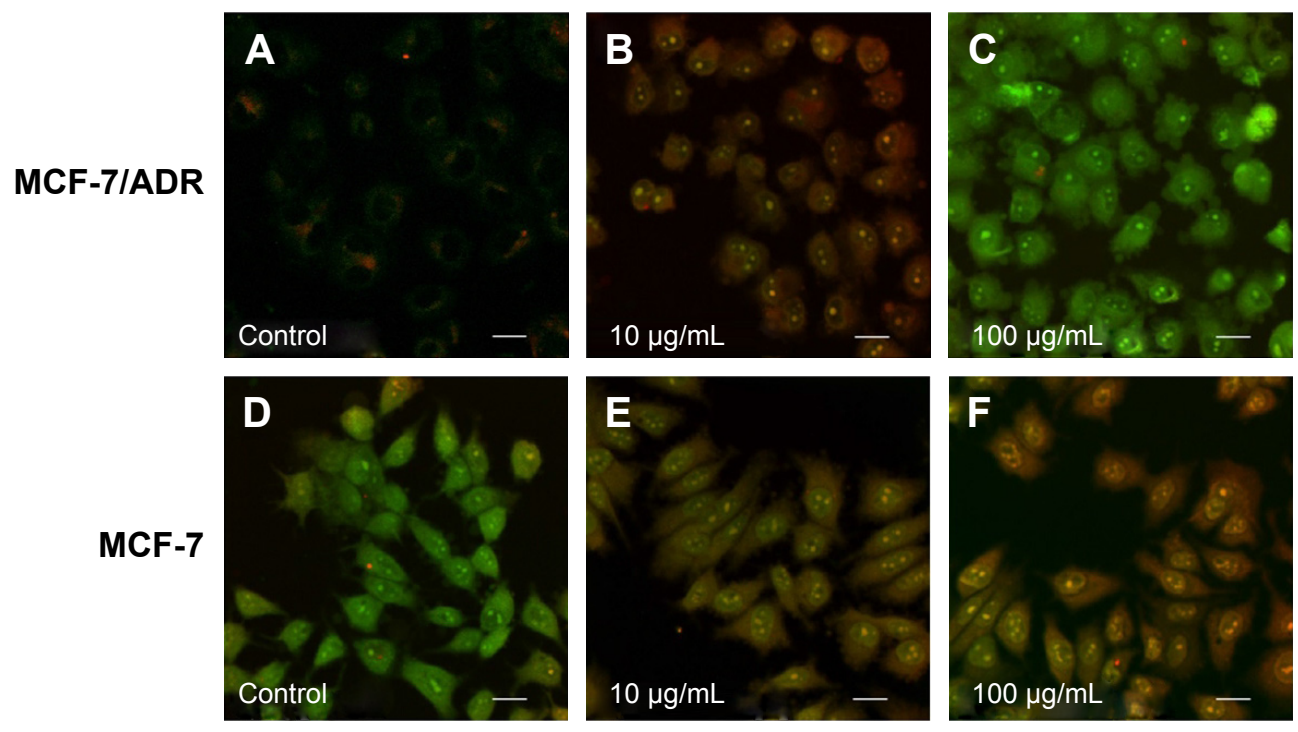

Figure 8 LSCM images of MCF-7 and MCF-7/ADR cells showing the integrity of the lysosomal membrane visualized by AO staining.

Notes: (A, D) Cells incubated with AO alone; (B, E) cells incubated with $10 \mu \mathrm{g} / \mathrm{mL}$ PAMAM-NH $\mathrm{H}_{2}$ for 2 hours; and $(\mathbf{C}, \mathbf{F})$ cells incubated with I00 $\mu \mathrm{g} / \mathrm{mL}$ PAMAM-NH for 2 hours. The scale bar is $20 \mu \mathrm{m}$.

Abbreviations: AO, Acridine Orange; LSCM, laser scanning confocal microscope. 
A

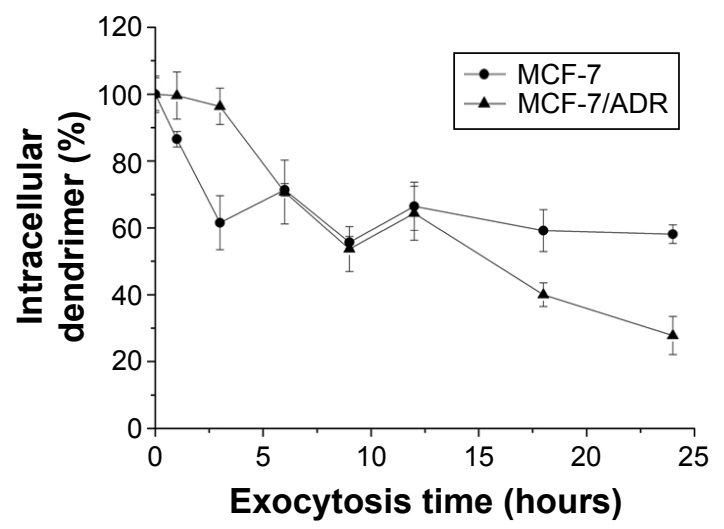

B Nucleus
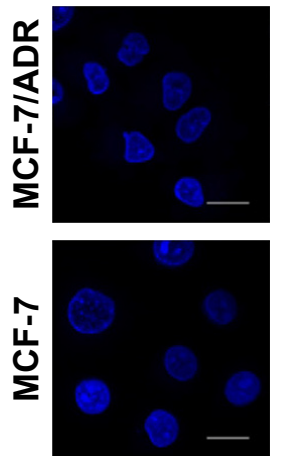

PAMAM- $\mathrm{NH}_{2}$
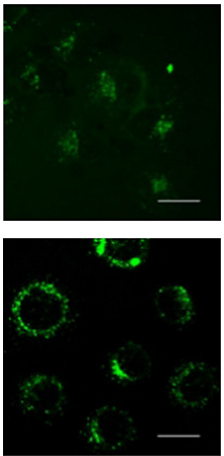

Merge
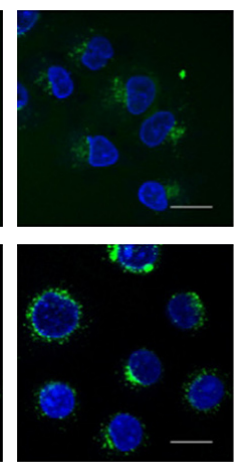

Figure 9 The exocytosis of PAMAM-NH $\mathrm{N}_{2}$ in the MCF-7 and MCF-7/ADR cells.

Notes: (A) The amount of intracellular PAMAM-NH $\mathrm{N}_{2}$ at different exocytosis times in the MCF-7 and MCF-7/ADR cells. All values are relative to the amount at 0 hour (mean $\pm \mathrm{SD}, \mathrm{n}=3$ ). (B) The confocal microscope images of exocytosis for PAMAM-NH $\mathrm{NH}_{2}$ in $\mathrm{MCF}-7$ and MCF-7/ADR cells for 4 hours. PAMAM-NH ${ }_{2}$ was green, while the nucleuses were blue stained using Hoechst 33258. The scale bar is $20 \mu \mathrm{m}$.

Abbreviation: SD, standard deviation.

around $60 \%$ of PAMAM-NH $\mathrm{N}_{2}$ was retained in MCF-7 cells at 24 hours. The intracellular PAMAM-NH ${ }_{2}$ in the MCF-7/ADR cells, in contrast, declined steadily after 3 hours, finally reaching $27.8 \%$ at 24 hours. Hence, the exocytosis of PAMAM$\mathrm{NH}_{2}$ from the MCF-7/ADR cells was much greater than that from the MCF-7 cells.

As shown in Figure 9B, the green fluorescence did not overlap with the blue fluorescence, indicating that the PAMAM- $\mathrm{NH}_{2}$ was rapidly eliminated from the nucleus. The green fluorescence intensity was lower in the MCF-7/ADR cells than that in the MCF-7 cells, suggesting that the remaining PAMAM-NH in the MCF-7/ADR cells was less than that in the MCF-7 cells. This was consistent with the flow cytometer results (Figure 9A), and the remaining PAMAM-NH $\mathrm{N}_{2}$ observed in Figure 9A were the portion of PAMAM-NH $\mathrm{N}_{2}$ that was retained in the cytoplasm in MCF-7 and MCF-7/ADR cells.

Commonly, exocytosis is a process by which material is exported from a biological cell. We estimated the remaining fluorescence signals in the cell in our study, which included degradation in addition to exocytosis. It is reported that the lysosomal pathway is a degradation route for most macromolecules. ${ }^{18}$ The bafilomycin A1, an inhibition of acidification, may prevent macromolecules from being transported to lysosomes, resulting in the avoidance of degradation. ${ }^{18}$ As shown in Figure 10A, the remaining PAMAM- $\mathrm{NH}_{2}$ in the
A

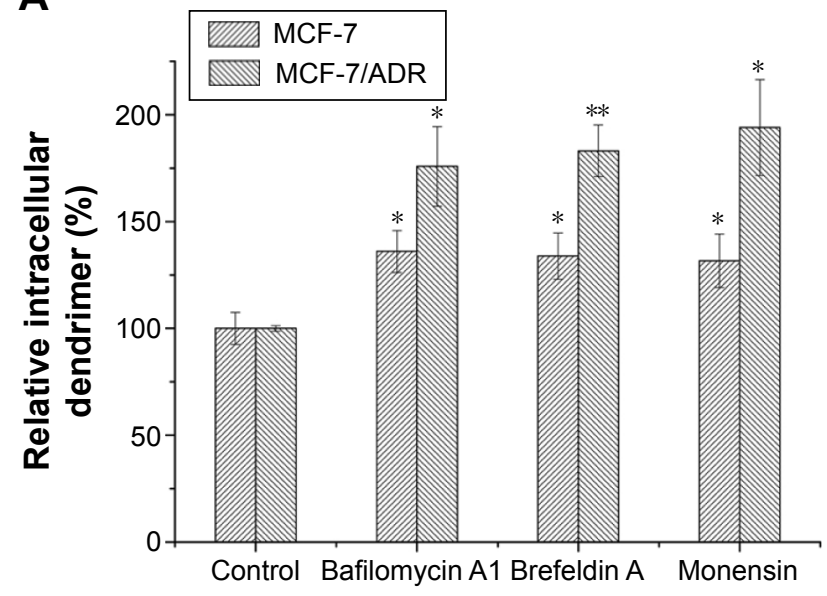

B

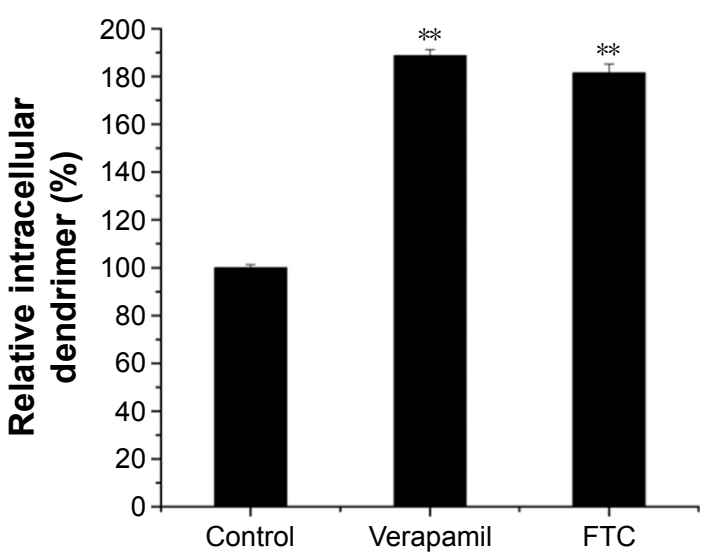

Figure 10 The effects of different inhibitors on the exocytosis of PAMAM- $\mathrm{NH}_{2}$.

Notes: The control samples were cells with no inhibitor pretreatment. *Indicates $P<0.05$ vs control group, ${ }^{*} *$ indicates $P<0.0$ I vs control group. (A) The effects of different intracellular transport inhibitors on the exocytosis of PAMAM-NH $\mathrm{H}_{2}$ in MCF-7 and MCF-7/ADR cells (mean \pm SD, $n=3$ ). (B) The effects of P-gP and MDR-associated protein inhibitors on the exocytosis of PAMAM-NH $\mathrm{N}_{2}$ in MCF-7/ADR cells (mean $\pm \mathrm{SD}, \mathrm{n}=3$ ).

Abbreviations: FTC, fumitremorgin C; P-gp, P-glycoprotein; SD, standard deviation; MDR, multidrug resistance. 
MCF-7 and MCF-7/ADR cells increased with the addition of bafilomycin A1, indicating that inhibition of endosomal acidification decreases the degradation of PAMAM-NH$H_{2}$. Figure $10 \mathrm{~A}$ also showed that the remaining PAMAM-NH $\mathrm{N}_{2}$ in two types of cells increased with the addition of brefeldin A and monensin, demonstrating that inhibition of the Golgi complex and ER decreases the exocytosis of PAMAM-NH${ }_{2}$. Therefore, we concluded that these two processes, namely, transportation from the ER to the Golgi complex and transportation from the Golgi complex to the plasma membrane, participated in the exocytosis of PAMAM-NH $\mathrm{H}_{2}$ in both the MCF-7 and MCF-7/ADR cells. The endosomal acidification participated in the degradation of PAMAM-NH $\mathrm{N}_{2}$ in both the MCF-7 and MCF-7/ADR cells. Thus, the greater exocytosis observed in the MCF-7/ADR cells did not stem primarily from these processes.

We have also demonstrated that P-gp and MDR-associated protein can influence the endocytosis of PAMAM-NH $\mathrm{H}_{2}$ in MCF-7/ADR cells (Figure 3) relative to MCF-7 cells. To investigate the contribution of $\mathrm{P}$-gp and MDR-associated protein to the exocytosis of PAMAM-NH,$~ V R P$, and FTC were added separately as inhibitory agents. Figure 10B shows that the remaining PAMAM-NH $\mathrm{N}_{2}$ in the MCF-7/ADR cells increased to an extremely significant degree $(P<0.01)$ with the addition of VRP and FTC, suggesting that P-gp and MDR-associated protein play an important role in the exocytosis of PAMAM-NH $\mathrm{N}_{2}$ in MCF-7/ADR cells. Therefore, the PAMAM-NH $\mathrm{N}_{2}$ excreted by P-gp and MDR-associated protein caused more exocytosis of PAMAM-NH MCF-7/ADR cells than in the MCF-7 cells.

The exocytosis of PAMAM-NH $\mathrm{N}_{2}$ in cells is complex and involves different structures and organelles. ${ }^{18}$ Our results demonstrate that, compared with their role in MCF-7 cells, in addition to the ER, Golgi complex, and lysosomes, both P-gp and MDR-associated protein also play an important role in the exocytosis process of PAMAM- $\mathrm{NH}_{2}$ in MCF-7/ADR cells, resulting in its continuous exocytosis in MCF-7/ADR cells.

\section{Conclusion}

PAMAM-NH ${ }_{2}$, which is used as a drug and gene carriers to reverse $\mathrm{MDR}$, has attracted increased research attention in recent years. However, there have been few reports on its transportation in resistant cells. In this study, MCF-7/ADR cells were employed to investigate the transportation mechanisms of PAMAM- $\mathrm{NH}_{2}$, with the sensitive

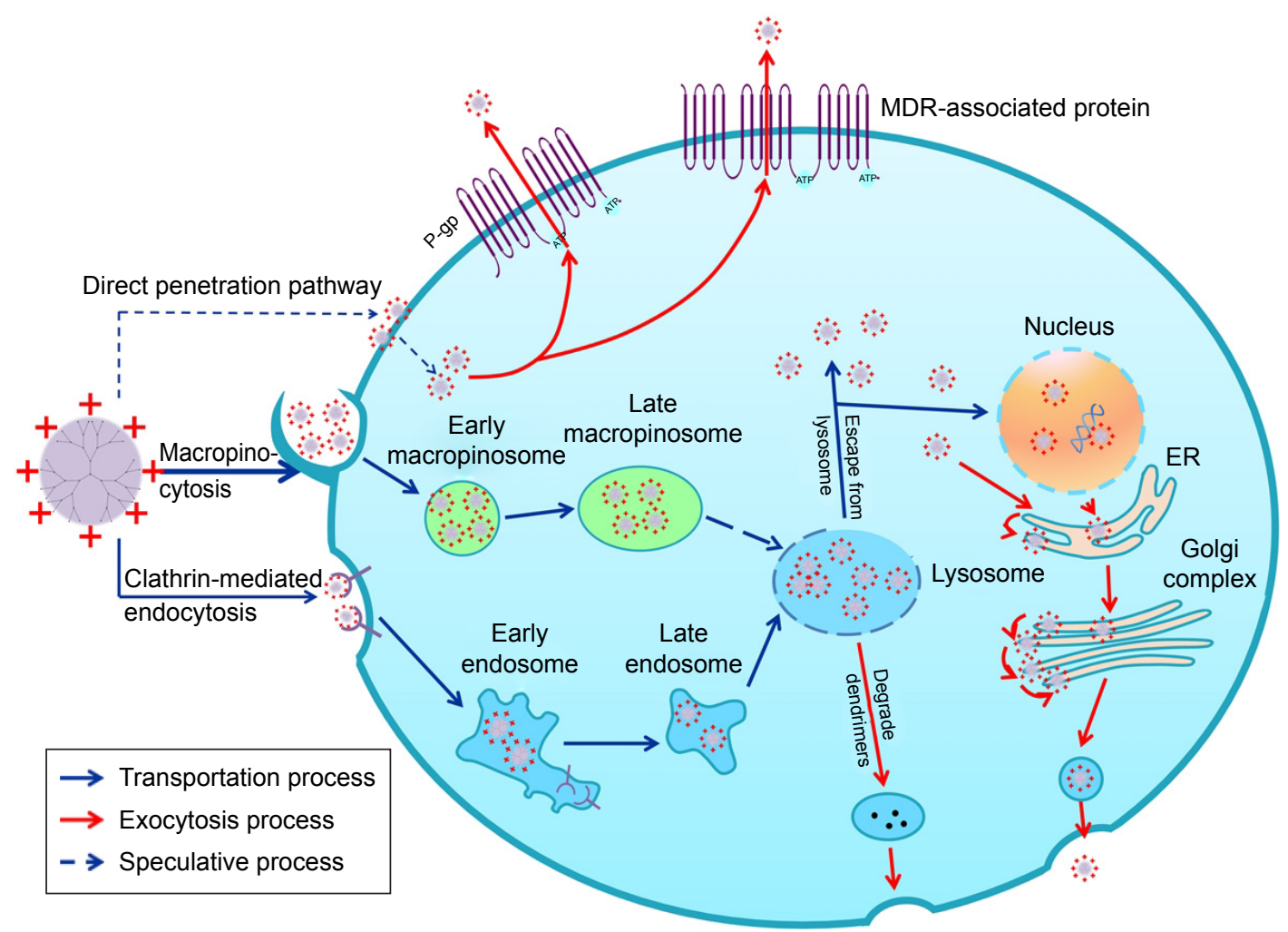

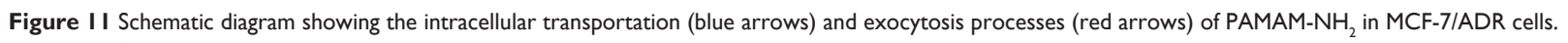
Abbreviations: ER, endoplasmic reticulum; MDR, multidrug resistance; P-gp, P-glycoprotein. 
cells (MCF-7 cells) used as a control. The results indicate that P-gp and MDR-associated protein resulted in much greater PAMAM-NH${ }_{2}$ exocytosis and lower PAMAM-NH endocytosis in the MCF-7/ADR cells than in the MCF-7 cells. The macropinocytosis played a more important role in PAMAM-NH $\mathrm{N}_{2}$ uptake pathway in the MCF-7/ADR cells than the MCF-7 cells. The PAMAM-NH ${ }_{2}$ aggregated and was degraded more in the lysosomal vesicles of the MCF-7/ADR cells than in those of the MCF-7 cells. The exocytosis of PAMAM-NH$H_{2}$ dendrimers was observed in MCF-7/ADR cells. The ER and Golgi complex were two important regulatory organelles for the exocytosis of PAMAM-NH $\mathrm{N}_{2}$ in both MCF-7 and MCF-7/ADR cells. The lysosomes participated in the degradation of PAMAM- $\mathrm{NH}_{2}$ in both the MCF-7 and MCF-7/ADR cells. A schematic diagram of the transportation processes of PAMAM- $\mathrm{NH}_{2}$ in MCF-7/ADR cells is presented in Figure 11. Our results afford a more comprehensive understanding of PAMAM$\mathrm{NH}_{2}$ transportation in MCF-7/ADR cells and may provide further guidance on the design of promising PAMAM- $\mathrm{NH}_{2}$ systems with high-efficiency transportation in both sensitive and resistant cells.

\section{Acknowledgment}

The authors are grateful to the Natural Science Foundation Committee of China for financial support (number 81202483 and number 81102400).

\section{Disclosure}

The authors report no conflicts of interest in this work.

\section{References}

1. Hsieh M-J, Chen M-K, Yu Y-Y, Sheu G-T, Chiou H-L. Psoralen reverses docetaxel-induced multidrug resistance in A549/D16 human lung cancer cells lines. Phytomedicine. 2014;21(7):970-977.

2. Saraswathy M, Gong S. Different strategies to overcome multidrug resistance in cancer. Biotechnol Adv. 2013;31(8):1397-1407.

3. Patel NR, Pattni BS, Abouzeid AH, Torchilin VP. Nanopreparations to overcome multidrug resistance in cancer. Adv Drug Deliv Rev. 2013; 65(13-14):1748-1762.

4. Gao Z, Zhang L, Sun Y. Nanotechnology applied to overcome tumor drug resistance. J Control Release. 2012;162(1):45-55.

5. Mu C-F, Balakrishnan P, Cui F-D, et al. The effects of mixed MPEGPLA/Pluronic ${ }^{\circledR}$ copolymer micelles on the bioavailability and multidrug resistance of docetaxel. Biomaterials. 2010;31(8):2371-2379.

6. Zhang P, Ling G, Pan X, et al. Novel nanostructured lipid-dextran sulfate hybrid carriers overcome tumor multidrug resistance of mitoxantrone hydrochloride. Nanomedicine. 2012;8(2):185-193.

7. Zhang X, Li F, Guo S, et al. Biofunctionalized polymer-lipid supported mesoporous silica nanoparticles for release of chemotherapeutics in multidrug resistant cancer cells. Biomaterials. 2014;35(11):3650-3665.

8. Yabbarov NG, Posypanova GA, Vorontsov EA, Obydenny SI, Severin ES. A new system for targeted delivery of doxorubicin into tumor cells. $J$ Control Release. 2013;168(2):135-141.
9. Kesharwani P, Jain K, Jain NK. Dendrimer as nanocarrier for drug delivery. Prog Polym Sci. 2014;39(2):268-307.

10. Han M, Lv Q, Tang X-J, et al. Overcoming drug resistance of MCF-7/ADR cells by altering intracellular distribution of doxorubicin via MVP knockdown with a novel siRNA polyamidoamine-hyaluronic acid complex. J Control Release. 2012;163(2):136-144.

11. Zheng W, Cao C, Liu Y, et al. Multifunctional polyamidoaminemodified selenium nanoparticles dual-delivering siRNA and cisplatin to A549/DDP cells for reversal multidrug resistance. Acta Biomater. 2015; 11:368-380.

12. Hong W, Chen D, Zhang X, et al. Reversing multidrug resistance by intracellular delivery of Pluronic ${ }^{\circledR}$ P85 unimers. Biomaterials. 2013;34(37):9602-9614.

13. Wang M, Hu H, Sun Y, et al. A pH-sensitive gene delivery system based on folic acid-PEG-chitosan - PAMAM-plasmid DNA complexes for cancer cell targeting. Biomaterials. 2013;34(38):10120-10132.

14. Perumal OP, Inapagolla R, Kannan S, Kannan RM. The effect of surface functionality on cellular trafficking of dendrimers. Biomaterials. 2008;29(24-25):3469-3476.

15. Albertazzi L, Serresi M, Albanese A, Beltram F. Dendrimer internalization and intracellular trafficking in living cells. Mol Pharm. 2010;7(3): 680-688.

16. Kitchens KM, Foraker AB, Kolhatkar RB, Swaan PW, Ghandehari H. Endocytosis and interaction of poly (amidoamine) dendrimers with caco-2 cells. Pharm Res. 2007;24(11):2138-2145.

17. Nam HY, Kwon SM, Chung H, et al. Cellular uptake mechanism and intracellular fate of hydrophobically modified glycol chitosan nanoparticles. J Control Release. 2009;135(3):259-267.

18. Chai G-H, Hu F-Q, Sun J, Du Y-Z, You J, Yuan H. Transport pathways of solid lipid nanoparticles across Madin-Darby canine kidney epithelial cell monolayer. Mol Pharm. 2014;11:3716-3726.

19. Nogueira DR, Tavano L, Mitjans M, Pérez L, Infante MR, Vinardell MP. In vitro antitumor activity of methotrexate via $\mathrm{pH}$-sensitive chitosan nanoparticles. Biomaterials. 2013;34(11):2758-2772.

20. Fuchs S, Kapp T, Otto H, et al. A surface-modified dendrimer set for potential application as drug delivery vehicles: synthesis, in vitro toxicity, and intracellular localization. Chemistry. 2004;10(5):1167-1192.

21. Seib FP, Jones AT, Duncan R. Comparison of the endocytic properties of linear and branched PEIs, and cationic PAMAM dendrimers in B16f10 melanoma cells. J Control Release. 2007;117(3):291-300.

22. Martínez-Zaguilán R, Raghunand N, Lynch RM, et al. pH and drug resistance. I. functional expression of plasmalemmal V-type $\mathrm{H}^{+}$-ATPase in drug-resistant human breast carcinoma cell lines. Biochem Pharmacol. 1999;57:1037-1046.

23. Liu P, Sun Y, Wang Q, Sun Y, Li H, Duan Y. Intracellular trafficking and cellular uptake mechanism of mPEG-PLGA-PLL and mPEGPLGA-PLL-Gal nanoparticles for targeted delivery to hepatomas. Biomaterials. 2014;35(2):760-770.

24. Litman T, Druley TE, Stein WD, Bates SE. From MDR to MXR: new understanding of multidrug resistance systems, their properties and clinical significance. Cell Mol Life Sci. 2001;58(7):931-959.

25. Gekeler V, Ise W, Sanders KH, Ulrich W-R, Beck J. The leukotriene LTC4 receptor antagonist MK571 specifically modulates MRP associated multidrug resistance. Biochem Biophys Res Commun. 1995;208(1): $345-352$.

26. Loevezijin Av, Allen JD, Schinkel AH, Koomen GJ. Inhibition of BCRP-Mediated drug efflux by fumitremorgin-type indolyl diketopiperazines. Bioorg Med Chem Lett. 2001;11(1):29-32.

27. Xue P, Yang X, Liu Y, Xiong C, Ruan J. A novel compound RY10-4 downregulates P-glycoprotein expression and reverses multidrugresistant phenotype in human breast cancer MCF-7/ADR cells. Biomed Pharmacother. 2014;68(8):1049-1056.

28. Kolhatkar RB, Kitchens KM, Swaan PW, Ghandehari H. Surface acetylation of polyamidoamine (PAMAM) dendrimers decreases cytotoxicity while maintaining membrane permeability. Bioconjug Chem. 2007;18(6):2054-2060. 
29. Leroueil PR, Hong S, Mecke A, Baker JR Jr, Orr BG, Banaszak Holl MM. Nanoparticle interaction with biological membranes: does nanotechnology present a Janus face? Acc Chem Res. 2007;40(5):335-342.

30. Mecke A, Lee D-K, Ramamoorthy A, Orr BG, Banaszak Holl MM. Synthetic and natural polycationic polymer nanoparticles interact selectively with fluid-phase domains of DMPC lipid bilayers. Langmuir. 2005;21(19):8588-8590.

31. Xiang S, Tong H, Shi Q, et al. Uptake mechanisms of non-viral gene delivery. J Control Release. 2012;158(3):371-378.

32. Huth US, Schubert R, Peschka-Süss R. Investigating the uptake and intracellular fate of $\mathrm{pH}$-sensitive liposomes by flow cytometry and spectral bio-imaging. J Control Release. 2006;110(3):490-504.

33. van der Aa MA, Huth US, Hafele SY, et al. Cellular uptake of cationic polymer-DNA complexes via caveolae plays a pivotal role in gene transfection in COS-7 cells. Pharm Res. 2007;24(8):1590-1598.

34. West MA, Bretscher MS, Watts C. Distinct endocytotic pathways in epidermal growth factor-stimulated human carcinoma A431 cells. J Cell Biol. 1989;109(6 Pt 1):2731-2739.

35. Miller SG, Carnell L, Moore H-PH. Post-Golgi membrane traffic: brefeldin A inhibits export from distal Golgi compartments to the cell surface but not recycling. J Cell Biol. 1992;112(2):267-283.

36. Kuismanen E, Saraste J, Pettersson RF. Effect of monensin on the assembly of Uukuniemi virus in the Golgi complex. J Virol. 1985;55(3): 813-822.

37. Hagiwara K, Nakata M, Koyama Y, Sato T. The effects of coating $\mathrm{pDNA} /$ chitosan complexes with chondroitin sulfate on physicochemical characteristics and cell transfection. Biomaterials. 2012; 33(29):7251-7260.
38. Pearse BM. Clathrin: a unique protein associated with intracellular transfer of membrane by coated vesicles. Proc Natl Acad Sci USA. 1976;73(4): 1255-1259.

39. Rappoport JZ. Focusing on clathrin-mediated endocytosis. Biochem J. 2008;412(3):415-423.

40. Luzio JP, Parkinson MD, Gray SR, Bright NA. The delivery of endocytosed cargo to lysosomes. Biochem Soc Trans. 2009;37(Pt 5): 1019-1021.

41. Brunner S, Sauer T, Carotta S, Cotten M, Saltik M, Wagner E. Cell cycle dependence of gene transfer by lipoplex, polyplex and recombinant adenovirus. Gene Ther. 2000;7:401-407.

42. Hillaireau H, Couvreur P. Nanocarriers' entry into the cell: relevance to drug delivery. Cell Mol Life Sci. 2009;66:2873-2896.

43. Hewlett LJ, Prescott AR, Watts C. The coated pit and macropinocytic pathways serve distinct endosome populations. J Cell Biol. 1994; 124(5):689-703.

44. Sohaebuddin SK, Thevenot PT, Baker D, Eaton JW, Tang L. Nanomaterial cytotoxicity is composition, size, and cell type dependent. Part Fibre Toxicol. 2010;7:22.

45. Wang P, Zhao X-H, Wang Z-Y, Meng M, Li X, Ning Q. Generation 4 polyamidoamine dendrimers is a novel candidate of nano-carrier for gene delivery agents in breast cancer treatment. Cancer Lett. 2010; 298(1):34-49.
International Journal of Nanomedicine

\section{Publish your work in this journal}

The International Journal of Nanomedicine is an international, peerreviewed journal focusing on the application of nanotechnology in diagnostics, therapeutics, and drug delivery systems throughout the biomedical field. This journal is indexed on PubMed Central,

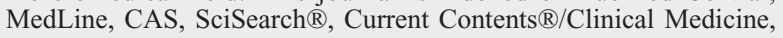

\section{Dovepress}

Journal Citation Reports/Science Edition, EMBase, Scopus and the Elsevier Bibliographic databases. The manuscript management system is completely online and includes a very quick and fair peer-review system, which is all easy to use. Visit http://www.dovepress.com/ testimonials.php to read real quotes from published authors. 